\title{
Aspectos gerais e diagnóstico clinicolaboratorial da intoxicação por paraquat
}

\section{General aspects and clinical laboratorial diagnostic of poisoning by paraquat}

Gabriela Cristina Schmitt'; Clóvis Paniz'; Denise Grotto'; Juliana Valentini'; Karen Lilian Schott';

Valdeci Juarez Pomblum²; Solange Cristina Garcia ${ }^{3}$

\begin{abstract}
unitermos resumo
Paraquat

Introdução: O paraquat, herbicida amplamente utilizado na agricultura, é um produto perigoso, pois pode causar intoxicações fatais, principalmente pela falta de antídoto eficaz para reversão do quadro

Toxicidade clínico. Fisiopatologia: Os efeitos toxicológicos são decorrentes da indução ao estresse oxidativo. O ór-

Estresse oxidativo gão-alvo principal é o pulmão, que pode apresentar edema, hemorragia, inflamação intersticial e fibrose, Material biológico culminando com falência respiratória grave e morte. Além disso, é nefrotóxico, hepatotóxico, miotóxico e neurotóxico. Tratamento: Além de visar a diminuição da absorção e estimular a excreção do paraquat Diagnóstico laboratorial absorvido, o tratamento da intoxicação atualmente é baseado em medidas que diminuam o estresse oxidativo utilizando substâncias antioxidantes e, conseqüentemente, revertam o quadro toxicológico instalado, especialmente o pulmonar. Métodos diagnósticos: Entre as metodologias quantitativas disponíveis, os métodos cromatográficos são os mais relatados para materiais biológicos. Porém, a eletroforese capilar e os imunoensaios podem ser utilizados. Os imunoensaios destacam-se pela praticidade laboratorial, pois os cromatográficos e eletroforéticos não são encontrados comumente em laboratórios hospitalares. Por outro lado, uma reação simples e rápida de caracterização urinária com ditionito de sódio é muito realizada, pois é preditiva na suspeita de intoxicações agudas. Conclusão: Diante do alto potencial de morbimortalidade nas intoxicações por paraquat, a reversão dos danos pulmonares com uso de antioxidantes vem sendo muito estudada, porém não há o estabelecimento de um antídoto específico. No diagnóstico laboratorial, métodos cromatográficos, eletroforéticos e imunológicos são usados para quantificá-lo, contudo a reação urinária com ditionito ainda é valiosa na rotina da toxicologia clínica.
\end{abstract}

abstract

Introduction: Paraquat is a herbicide widely used in agriculture. It is a very toxic product, fatally poisoning mainly by the lack of an efficient antidote to revert the clinical state. Fisiopathology: Toxicological effects are decurrent of oxidative stress. The most important target organ is the lung, which can display edema, hemorrhage, interstitial inflammation and fibroses, culminating in serious respiratory failure and death. Moreover, it is nephrotoxic, hepatotoxic, miotoxic and neurotoxic. Treatment: Besides aiming the decrease of absorption and stimulating the excretion of absorbed paraquat, the poisoning treatment nowadays is based on measures that decrease oxidative stress using antioxidants, consequently reverting clinical state, mainly the pulmonary. Diagnostic methods: Among the available quantitative methods, the chromatographic are the most reported ones for biological samples. However, capillary electrophoresis and immunoassay methods can be used. Immunoassays stand out for being typically found in hospital laboratories, while chromatographic and electrophoretic methods are not. On the other hand, a simple and fast urinary reaction with sodium dithionite is very utilized because it is predictive in acute poisoning suspect. Conclusion: In the presence of high morbimortality potential in paraquat intoxications, the reversion of pulmonary toxicity with antioxidants is extensively studied, but a specific antidote is not established. In laboratorial diagnostic, chromatographic, electrophoretic and immunologic techniques are applied to paraquat quantification, although in clinical toxicology the sodium dithionite reaction is still significant. key words

Paraquat

Toxicity

Oxidative stress

Biological sample

Laboratorial diagnostic

1. Farmacêuticos-bioquímicos do Laboratório de Toxicologia (LATOX), Departamento de Análises Clínicas e Toxicológicas da Universidade Federal de Santa Maria (UFSM).

2. Professor-doutor em Medicina, Departamento de Clínica Médica da UFSM.

3. Professora-doutora em Farmácia, Departamento de Análises Clínicas e Toxicológicas da UFSM. 


\section{Introdução}

Intoxicações por praguicidas e outras substâncias químicas utilizadas na agricultura representam um problema de saúde pública mundial. São notificadas aproximadamente 20 mil fatalidades anuais e mais de 2 milhões de hospitalizações por essa razão. Nos Estados Unidos, cerca de 340 mil casos de intoxicações por praguicidas agrícolas foram registrados entre 1985 e $1990^{(27)}$. No Brasil, as intoxicações agudas em agricultores intensificaram-se e, segundo Rüegg, há ocorrência de um caso agudo a cada oito trabalhadores agrícolas examinados ${ }^{(59)}$.

Estima-se ainda que cerca de $2 \%$ da população brasileira seja contaminada anualmente por praguicidas e que para cada caso constatado em hospitais e ambulatórios deva haver em torno de 250 vítimas não-registradas, principalmente pela falta de conhecimentos clinicotoxicológicos ${ }^{(26,30)}$.

O paraquat é um herbicida muito utilizado na agricultura e merece destaque especial dentro da classe dos praguicidas devido ao alto índice de intoxicações e fatalidades que lhe são atribuídas, sejam elas acidentais ou propositais, correspondendo a $0,34 \%$ de todos os casos. Entretanto, ele é responsável por $13 \%$ do total de mortes decorrentes de intoxicações por praguicidas e outras substâncias químicas ${ }^{(41)}$. O Japão é o país que tem registrado o maior número de fatalidades: mais de mil por ano. Na Irlanda, a mortalidade chega a $78 \%$ e na Costa Rica, a $60 \%{ }^{(77)}$.

Seu índice de mortalidade é superior a $70 \%(47)$, principalmente pela falta de um antídoto eficaz que reverta o quadro clínico do paciente ${ }^{(61)}$. Sua toxicidade atinge vários órgãos, incluindo pulmões, fígado, cérebro, rins, coração, adrenais e músculos $(10,17,63)$, mas o principal dano ocorre nos pulmões, culminando em falência respiratória e morte(47).

Vários países suspenderam ou restringiram severamente o uso de paraquat ${ }^{(22)}$, além de adotarem medidas, como diminuir sua concentração e acrescentar substâncias odoríferas, corantes e eméticas nas preparações comerciais ${ }^{(77)}$. Porém, em muitos países ainda há uso indiscriminado do herbicida, aumentando os índices de morbimortalidade mundiais(23).

Nesse sentido, esta revisão pretende apontar aspectos gerais da intoxicação humana por paraquat, suas implicações patológicas, diagnóstico laboratorial e tratamento.

\section{Aspectos gerais e históricos do herbicida}

O paraquat (1,1'-dimetil-4,4'-bipiridilo), um herbicida de contato não-seletivo, é amplamente utilizado em mais de cem países em culturas de fumo, algodão, arroz, café, cana-de-açúcar, feijão, maçã, soja e uva, entre outras ${ }^{(54)}$.

Ele não existe em estado natural. Sua síntese deve-se a Widel e Russo, que publicaram seus trabalhos em 1882. No entanto, as propriedades herbicidas do produto só foram descobertas em 1955(61), e sua utilização começou em $1962^{(35)}$. Os primeiros casos fatais foram acidentais e ocorreram em 1964, mas só foram relatados em $1966^{(10)}$. Desde então, têm sido reportadas várias mortes resultantes de intoxicações ocupacionais, acidentais ou suicidas ${ }^{(23,43,58,62)}$.

É um sólido incolor, cristalino e higroscópico cuja fórmula molecular é $\mathrm{C}_{12} \mathrm{H}_{14} \mathrm{~N}_{2}$ com peso molecular de 186,25 . Na forma de dicloreto é representado pela fórmula $\mathrm{C}_{12} \mathrm{H}_{14} \mathrm{~N}_{2} \mathrm{Cl}_{2^{\prime}}$ com peso molecular de $257,25^{(14)}$.

Não é volátil, explosivo ou inflamável em solução aquosa. É corrosivo para metais e estável em solução ácida ou neutra, mas se hidrolisa facilmente em meio alcalino. Os seus sais são eletrólitos fortes que, em solução, dissociam-se em uma grande quantidade de íons positivos e negativos ${ }^{(61)}$. É solúvel em água, possui baixa solubilidade em álcoois e é insolúvel em hidrocarbonetos ${ }^{(14)}$.

Em geral, é conhecido e comercializado como Gramoxone ${ }^{\circledR}$, Gramoci ${ }^{\circledR}$, Agroquat $^{\circledR}$, Gramuron $^{\circledR}$, Paraquat $^{\circledR} \mathrm{e}$ Paraquo ${ }^{\circledast}$, ou também como constituinte em misturas com outros princípios ativos, como no Secamato ${ }^{\circledR(49)}$.

Em animais, a dose letal média $\left(\mathrm{LD}_{50}\right)$ oral varia de 22 a $262 \mathrm{mg} / \mathrm{kg}$, de acordo com a espécie ${ }^{(22)}$. Em humanos, não existe consenso, mas sabe-se que a ingestão de 10 a $15 \mathrm{ml}$ de uma solução a $20 \%$, concentração na qual o produto normalmente é comercializado, seria suficiente para provocar intoxicações fatais, embora existam relatos de fatalidades provocadas pela ingestão de apenas $1 \mathrm{ml}$ dessa solução(70).

\section{Toxicocinética}

Embora existam relatos de intoxicações por via dérmi$\mathrm{ca}^{(31)}$, vaginal(50), injeção intramuscular ${ }^{(15)}$, subcutânea ${ }^{(53)} \mathrm{e}$ endovenosa ${ }^{(38)}$, as intoxicações resultantes da ingestão de paraquat, acidentais ou suicidas, são as mais importantes do ponto de vista toxicológico ${ }^{(77)}$.

A pele íntegra é praticamente impermeável ao paraquat, mas torna-se permeável quando irritada ou ulcerada, podendo a úlcera ser produzida pelo contato prolongado ou pela elevada concentração do tóxico ${ }^{(68)}$.

A absorção digestiva é baixa ( $<10 \%$ da dose ingerida), mas rápida, com pico plasmático em torno de 2-4 horas, 
decaindo muito rapidamente, já que numa primeira fase a meia-vida de eliminação gira em torno de cinco horas ${ }^{(37)}$. Normalmente, o paraquat absorvido é eliminado através da via renal nas primeiras 12-24 horas, mas, devido à sua nefrotoxicidade, a eliminação pode ser prejudicada ${ }^{(13)}$.

A acumulação do herbicida ocorre principalmente nos pulmões, onde pode alcançar concentrações letais em menos de dez horas, além de rins, músculos, coração e fígado. Seu volume de distribuição é de 1,2 a 1,6l/kg. Os músculos atuam como reservatório, permitindo uma liberação lenta. Isso explica, em parte, sua detecção no plasma e na urina várias semanas ou meses após a ingestão(77).

\section{Mecanismo de ação e toxicidade}

O mecanismo bioquímico responsável pela toxicidade do paraquat em mamíferos não está totalmente esclarecido(32). Entretanto, tem sido proposto que o dano tecidual deve-se ao aumento da formação de radicais livres e espécies reativas de oxigênio, entre eles o radical superóxido $\left(\mathrm{O}_{2}^{-}\right)$, o peróxido de hidrogênio $\left(\mathrm{H}_{2} \mathrm{O}_{2}\right)$ e o radical hidroxila $\left(\mathrm{OH}^{\circ}\right)$, os quais são instáveis e reagem rapidamente com ácidos graxos, provocando lesão nas membranas, proteínas e $\mathrm{DNA}^{(54)}$.

O mecanismo bioquímico de toxicidade do paraquat é representado na Figura 1. Inicialmente, ele reage com uma substância doadora de elétrons, o fosfato de nicotinamida adenina dinucleotídeo (NADPH), sofrendo uma redução por ação da enzima NADPH-citocromo $P_{450}$ redutase, 0 que resulta na geração de um radical paraquat. Entretanto, sob condições aeróbicas, esse elétron é transferido ao oxigênio, que se transforma em ânion superóxido. Como há suprimento de oxigênio no tecido pulmonar, o radical paraquat rapidamente se auto-oxida, produzindo radicais superóxido e regenerando o paraquat ${ }^{(24,63)}$. Na presença de suprimento suficiente de equivalentes reduzidos (NADPH), repetidos ciclos de redução e reoxidação do herbicida podem ocorrer ${ }^{(54)}$.

$\mathrm{O} \mathrm{O}_{2}$ que se forma pode ser detoxificado pela ação da enzima superóxido dismutase (SOD), produzindo peróxido de hidrogênio. Esse produto formado é removido através da enzima catalase. Entretanto, a SOD pode ser suprimida pela grande quantidade de superóxido que vai sendo produzida quando há altas doses de paraquat. Dessa forma, os ânions superóxido sofrem uma reação de dismutação não-enzimática, formando o oxigênio singlete, que ataca os lipídios insaturados das membranas celulares, e dando origem a radicais livres lipídicos que, espontaneamente, geram radicais peroxil lipídicos. Esses podem reagir com

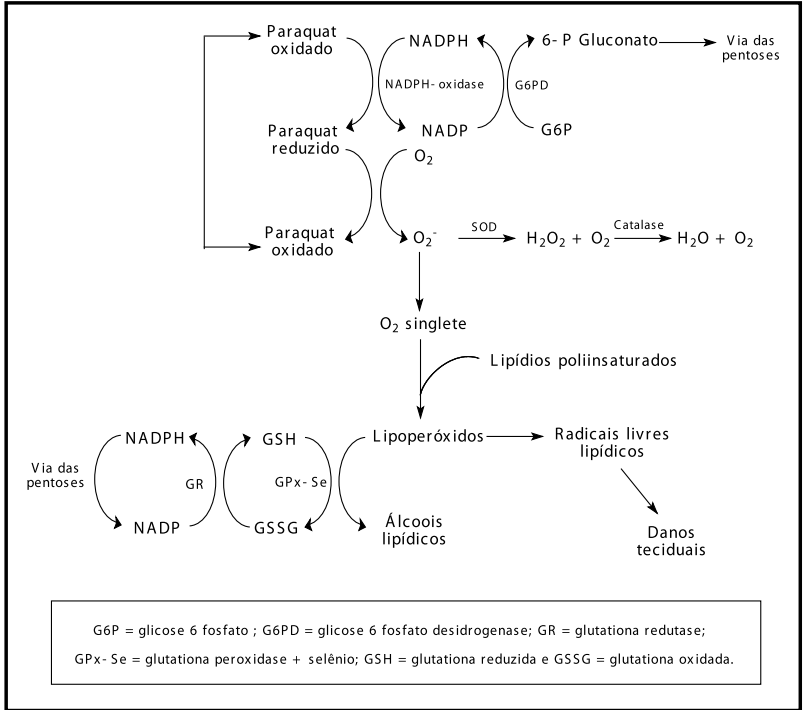

Figura 1 - Formação de radicais livres aumentada via paraquat com conseqüente lipoperoxidação e dano tecidual, segundo Bus et al. modificado ${ }^{(11)}$

outros ácidos graxos poliinsaturados, produzindo um hidroperóxido lipídico e mais radicais livres lipídicos, propagando o processo continuamente como uma reação em cadeia chamada peroxidação lipídica ${ }^{(11,54)}$.

Em conseqüência, o balanço entre a geração de radicais de oxigênio e sua dissipação pelos sistemas celulares de defesa (SOD, catalase, peroxidase, glutationa, vitamina $\mathrm{E}$ ) é alterado, possibilitando que espécies reativas ataquem as biomoléculas, desencadeando o dano tecidual ${ }^{(54)}$.

\section{Quadro clínico da intoxicação}

Quando há contato com a pele, pode ocorrer irritação, ressecamento, descamação, dermatites, eritemas, bolhas e úlceras. $O$ contato com as unhas pode levar a amolecimento, descoloração assimétrica, deformações e alterações de crescimento $^{(6,13)}$.

Em caso de contato com os olhos pode ocorrer irritação, com evolução para necrose conjuntival, ceratite progressiva com opacificação da córnea e diminuição da acuidade visual(75).

Após ingestão, os sintomas iniciais incluem dor e queimação em boca, faringe, esôfago e abdômen, irritação gastrintestinal, náuseas, vômitos e diarréia ${ }^{(65)}$, além de úlcera local e/ou necrose tecidual. Embora rara, a perfuração do esôfago pode ocorrer ${ }^{(36)}$.

Em ingestões maciças, a morte geralmente ocorre como resultado de injúrias cáusticas no trato gastrintestinal, associadas à falência circulatória e à chamada síndrome da angústia respiratória. Quando a 
exposição é menos severa, a falência respiratória fatal desenvolve-se como conseqüência da progressiva fibrose pulmonar ${ }^{(43)}$.

Alguns sintomas gerais como tonturas, cefaléia, febre, mialgias, letargia e coma são comuns. O coma pode ocorrer na fase final da intoxicação, em conseqüência da hipóxia ${ }^{(49)}$.

Os pulmões são os órgãos-alvo principais nas intoxicações por esse herbicida ${ }^{(34)}$, levando a severas injúrias e fibrose, caracterizadas por edema, hemorragia, inflamação intersticial e proliferação das células epiteliais brônquicas ${ }^{(63)}$. O herbicida acumula-se nas células epiteliais alveolares (pneumócitos) do tipo I e ll e nas células de Clara por meio de transporte ativo ${ }^{(34)}$. As alterações respiratórias podem ser evidenciadas pela ocorrência de tosse, dispnéia, taquipnéia, queda na curva de saturação da hemoglobina, diminuição da tolerância a esforço físico, cianose periférica e hipoxemia ${ }^{(49)}$. Através de um exame radiográfico do tórax pode-se perceber edema pulmonar bilateral, hipotransparências coalescentes e, posteriormente, fibrose pulmonar ${ }^{(61)}$.

Além disso, outros órgãos também são atingidos. No fígado, observa-se degeneração de hepatócitos na região periportal; esporadicamente, necrose celular da região central dos lóbulos hepáticos, provocando icterícia. É possível que ocorra colestase, inflamação portal, edema e degeneração ou necrose dos canais biliares tanto intra como extra-hepáticos e da vesícula biliar, assim como estase do canal pancreático ${ }^{(43)}$.

A patogênese da lesão renal não está totalmente esclarecida, mas sabe-se que o paraquat provoca lesões nos túbulos contorcidos proximais que podem culminar em insuficiência renal aguda ${ }^{(45)}$.

Como o paraquat possui a capacidade de atravessar a barreira hematencefálica, podem ocorrer lesões no sistema nervoso central, principalmente nos neurônios dopaminérgicos do núcleo estriado ${ }^{(8)}$. Ingestão de doses muito elevadas pode provocar quadros de ansiedade, convulsões, ataxia e diminuição do estado de vigília(36).

No coração, observam-se alguns transtornos, como miocardite tóxica, arritmias e choque ${ }^{(42,69)}$.

Laboratorialmente, observam-se aumentos de aminotransferases, bilirrubina e amilase séricas devido a lesões no fígado, vesícula biliar e pâncreas ${ }^{(6,23)}$. Em conseqüência das lesões nos túbulos contorcidos proximais e da redução do volume plasmático, pela diurese e pelo deslocamento de fluidos teciduais para o lúmen intestinal, o intoxicado pode apresentar hiperazotemia, hipocalemia, hiponatremia, hipopotassemia ${ }^{(14,45)}$, proteinúria, albuminúria ${ }^{(14)}$, hematúria, piúria, oligúria, anúria ${ }^{(49)}$, glicosúria, aminoacidúria e diminuição da eliminação do paraquat por via renal. Em decorrência da falência cardíaca progressiva com necrose tecidual, há aumento das transaminases e da creatinoquinase (CK e fração CKMB) $)^{(13)}$.

\section{Diagnóstico toxicológico e metodologias disponíveis}

Vários métodos para determinação do paraquat têm sido descritos na literatura, incluindo métodos colorimétricos ${ }^{(13)}$, cromatográficos $^{(1,9,19,21,29,39,40,51,72)}$, eletroforéticos ${ }^{(71,74,76)}$ e imunológicos ${ }^{(7,18,25,48)}$.

As amostras biológicas utilizadas são as mais diversas, incluindo sangue total ${ }^{(29,40)}$, soro ${ }^{(39,71,74)}$, plasma hepariniza$\mathrm{do}^{(9,51)}$ e urina ${ }^{(74,76)}$. Na maioria dos casos, é necessário um prévio tratamento da amostra para remover os interferentes.

Os métodos de triagem, como a cromatografia em camada delgada (CCD) e as reações de caracterização, são rápidos, de baixo custo e qualitativos, permitindo identificar facilmente o paraquat em material biológico. Dessa forma, são muito utilizados na rotina clínica para diagnóstico toxicológico. A CCD pode ser empregada em diversos materiais biológicos, utilizando diferentes fases móveis( ${ }^{(72)}$.

Métodos colorimétricos, como as reações de caracterização, são rápidos e fáceis. O paraquat pode ser identificado na urina através do teste utilizando ditionito de sódio $1 \%$ em meio alcalino. A mudança de coloração da amostra para azul significa presença de paraquat em concentrações superiores a $0,5 \mathrm{mg} / \mathrm{l}$ na urina. A intensidade do azul varia de acordo com o grau de intoxicação e, portanto, com a gravidade do caso. Controles positivo e negativo devem ser empregados paralelamente ao teste $\mathrm{e}^{(13)}$.

A realização de uma triagem rápida para identificação do paraquat é importante para adequar as medidas clínicas dos primeiros socorros ao intoxicado. Porém sua quantificação constitui um procedimento fundamental durante 0 período de tratamento e recuperação, pois o herbicida não sofre biotransformações significativas no organismo ${ }^{(9)}$. Os valores fornecidos, relacionados ao tempo pós-intoxicação, permitem um prognóstico adequado do paciente, além de auxiliar a correta conduta terapêutica. Entre os métodos que possibilitam a quantificação do herbicida encontram-se: cromatografia gasosa (CG), cromatografia gás-líquido (CGL), cromatografia líquida de alta eficiência (CLAE), eletroforese capilar (EC) e métodos imunológicos. 
A CG é aplicada na quantificação de paraquat em plasma humano. A amostra sofre redução com boroidreto de sódio, extração com solvente orgânico e detecção por ionização em chama, ionização em chama seletiva para nitrogênio ou espectrômetro de massas(21).

ACGL é utilizada na determinação de paraquat em sangue e urina. Sua utilização só é possível após preparo das amostras, que inclui formação de complexos do paraquat com reagente de Reinecke, posterior precipitação de proteínas com ácido perclórico ou tricloroacético e redução dos complexos com boroidreto de sódio, formando produtos peri-hidrogenados. A deteç̧ão se dá por ionização em chama ${ }^{(40)}$.

A CLAE é uma técnica analítica empregada nos métodos mais realizados e reportados na literatura. Há relatos de determinação do paraquat em plasma e soro desproteinizados com ácido perclórico em metanol, com detecção na região do ultravioleta (UV) ${ }^{(51)}$; plasma injetado diretamente em pré-colunas sílica alquil-diol (ADS) $C_{18}$ para prévia extração e análise posterior em $\mathrm{C}_{18}$ cromatográfica com detecção UV(9); sangue diluído em água, com adição de ácido tricloroacético, alcalinizado com $\mathrm{NaOH}$ e, posteriormente, extração sólido-líquido com cartuchos $\mathrm{C}_{18}$ e análise cromatográfica em $\mathrm{C}_{18}$ com deteç̧ão UV ${ }^{(29)}$; soro com adição de acetona, centrifugado e filtrado e detecção UV com auxílio de fotodiodo ${ }^{(39)}$; sangue, com precipitação de proteínas por ácido tricloroacético ou urina, seguida de redução com boroidreto de sódio e extração com solventes, sendo a quantificação com detector fotodiodo(1); e ainda em soro extraído por pareamento iônico em cartuchos de $\mathrm{C}_{18}$ com posterior separação analítica cromatográfica e detecção por UV ${ }^{(19)}$.

A EC pode ser aplicada na determinação do herbicida em soro e urina. Tomita et al. ${ }^{(71)}$ determinaram o herbicida em soro, após extração do analito em cartuchos de $\mathrm{C}_{18}$ e detecção UV, encontrando boa sensibilidade. Wu e Tsai ${ }^{(76)}$ quantificaram o paraquat na urina, comparando a sensibilidade da técnica com e sem prévio tratamento da amostra, sendo que a extraída em fase sólida apresentou melhor resultado. Em 2001, Vinner et al. aplicaram a EC em urina e soro, extraindo o analito com fenol liquefeito $\mathrm{e}$ submetendo o soro à desproteinização com clorofórmio e sulfato de amônio, com posterior detecção por UV ${ }^{(74)}$.

Os métodos imunológicos podem ser utilizados para triagem através de imunoensaio enzimático(1); ou na quantificação do paraquat através de radioimunoensaio (RIA) em soro ${ }^{(25)}$; plasma, urina e fluido do lavado broncoalveolar utilizando anticorpos monoclonais ${ }^{(7)}$; por enzyme linked immunosorbent assay (ELISA) em plasma ${ }^{(48)} \mathrm{e}$ imunoensaios com fluorescência em plasma ${ }^{(18)}$.
Segundo Proudfoot et al. ${ }^{(56)}$, a sobrevida do intoxicado depende da concentração da substância no organismo e do tempo após a ingestão. O ideal é que essa relação seja exponencialmente menor a partir das primeiras quatro horas após a exposição ao agente. Portanto, a quantificação plasmática do paraquat relacionada ao tempo após ingestão pode determinar o prognóstico do intoxicado. A Figura 2 mostra a relação entre os níveis plasmáticos do paraquat e o tempo após a sua ingestão, correlacionando a probabilidade percentual de recuperação do paciente ${ }^{(33)}$. Pode-se observar que uma concentração plasmática de $1 \mu \mathrm{g} / \mathrm{l}$ após quatro horas de ingestão representará $50 \%$ de chance de sobrevivência; se for menor que $0,5 \mu \mathrm{g} / \mathrm{l}$ poderá passar para até $90 \%$ de chance.

Assim, a determinação da concentração plasmática do herbicida pode ser determinante para o prognóstico de sobrevivência do indivíduo após intoxicação aguda por paraquat.

Apesar de ser muito importante quantificar o paraquat em materiais biológicos, nem sempre a aplicação dos métodos é possível, representando prejuízo terapêutico, pois aliada à dificuldade operacional imposta por algumas metodologias que exigem aparelhagem e reagentes de alto custo, há necessidade de pessoal técnico habilitado e rapidez no procedimento. Logo, as técnicas qualitativas, sobretudo o teste com ditionito de sódio $1 \%$ na urina para identificação do paraquat, ainda são as mais utilizadas na rotina clínica de urgência toxicológica.

A gasometria arterial seriada possui bom valor preditivo na evolução e no prognóstico do quadro. Para tanto, recentemente tem-se sugerido o uso do índice respiratório (IR) como método simples para prever a probabilidade de sobrevivência do paciente intoxicado. Valores de IR iguais ou maiores que 1,5 têm demonstrado possibilidade de sobrevivência reduzida ${ }^{(56,66)}$.



Figura 2 - Percentagem da probabilidade de sobrevivência do indivíduo após a ingestão do paraquat através da correlação da concentração plasmática em $\mu \mathrm{g} / \mathrm{l}$ e o tempo em horas após a ingestão, segundo Hart et al. modificado ${ }^{(33)}$ 
O cálculo do IR é realizado da seguinte forma ${ }^{(66)}$ :

$\mathrm{PAO}_{2}-\mathrm{PaO}_{2}=713 \times \mathrm{FIO}_{2}-\mathrm{PCO}_{2}\left[\mathrm{FIO}_{2}+\left(1-\mathrm{FIO}_{2}\right) / \mathrm{R}\right]-\mathrm{PO}_{2}$

Onde:

$\mathrm{PAO}_{2}-\mathrm{PaO}_{2}=$ capacidade de difusão do oxigênio do alvéolo para as artérias.

$\mathrm{FIO}_{2}=$ concentração do ar inspirado, em \%.

$\mathrm{PCO}_{2}=$ pressão parcial do dióxido de carbono, em mmHg.

$\mathrm{PO}_{2}=$ pressão parcial do oxigênio, em $\mathrm{mmHg}$.

$\mathrm{R}$ = coeficiente respiratório cujo valor-padrão é normalmente 0,8 .

\section{Tratamento}

Ainda não existe antídoto ou tratamento efetivo para amenizar os efeitos tóxicos do herbicidaa ${ }^{(65)}$. Mesmo assim, o tratamento baseia-se essencialmente em três pontos: prevenção da absorção, rápida excreção do paraquat absorvido e modificação dos efeitos teciduais do paraquat absorvido e não excretado(61).

\section{Prevenção da absorção}

Essa fase do tratamento é a mais importante. Geralmente, as seguintes medidas são indicadas:

- induzir vômitos utilizando substâncias eméticas como xarope de ipeca ou por estimulação mecânica;

- realizar lavagem gástrica;

- administrar substâncias adsorventes, como carvão ativado e terras argilosas (terra de Füller e bentonite), além de laxantes como o sulfato de magnésio e citrato de magnésio ${ }^{(6,61)}$.

\section{Excreção do paraquat absorvido}

Para aumentar a eliminação do herbicida, medidas como a diurese forçada, hemodiálise, hemoperfusão e plasmaférese podem ser $\operatorname{adotadas}^{(43,61)}$.

A diurese forçada é uma medida simples que pode ser instituída de forma rápida. É realizada com a utilização de substâncias como furosemida, manitol e suplementação de potássio(3).

A hemodiálise deve ser reservada a pacientes com insuficiência renal aguda ${ }^{(62)}$. Apesar de o paraquat não preencher os requisitos de um tóxico adequadamente dialisável por ter elevado volume de distribuição, elevado peso molecular e não se encontrar ligado às proteínas, a hemodiálise é um método útil quando as concentrações séricas de paraquat são elevadas e se for realizada nas primeiras 24 horas após a ingestão ${ }^{(61)}$.

A hemoperfusão é uma técnica que utiliza filtro de carbono ou poliestireno (resina), substitui o habitual filtro da hemodiálise e vai adsorver o tóxico. Sua realização constante e prolongada parece reduzir as reservas teciduais de paraquat ${ }^{(57)}$, mostrando-se eficiente em alguns $\operatorname{casos}^{(67)}$, embora sua utilização ainda apresente muitas controvérsias. Está indicada apenas quando há insuficiência renal ${ }^{(36)}$.

A plasmaférese é utilizada esporadicamente, possuindo capacidade depurativa semelhante à da hemoperfusão, mas sem alguns inconvenientes, como perda de células sangüíneas, necessidade de anticoagulação e inutilização do filtro adsorvente pela formação de trombos. Poderá apresentar como vantagens, esporadicamente, o fato de fornecer antioxidante renovado no plasma fresco infundido na substituição(55).

\section{Modificação dos efeitos teciduais do paraquat}

Sem dúvida, o maior interesse no tratamento das intoxicações por paraquat tem se concentrado em medidas que impeçam ou minimizem as lesões celulares provocadas, principalmente no nível pulmonar ${ }^{(61)}$. Nesse sentido, tem-se enfatizado a utilização de várias substâncias, entre elas as com ação antioxidante, como $\mathrm{N}$-acetilcisteína ${ }^{(46)}$, vitamina $\mathrm{C}^{(35)}$, vitamina $E^{(5)}$, SOD veiculada em lipossomas ${ }^{(2,4)}$, melatonina ${ }^{(12,44)}$, metalotioneína ${ }^{(20)}$ e quelantes do ferro, como a desferroxamina e a hidroxipiridina-4-ona ${ }^{(65)}$.

Além das substâncias com ação antioxidante, outras têm sido estudadas nos casos de intoxicação: betabloqueadores, por sua suposta capacidade de competir com os receptores pulmonares do paraquat ${ }^{(52) ;}$ ácidos graxos monoinsaturados, como o ácido oléico, pois o aumento de ácidos graxos monoinsaturados ou a diminuição dos insaturados nos lipídios das membranas diminui sua suscetibilidade aos ataques oxidativos ${ }^{(28,64)}$; anticorpos antiparaquat capazes de inibir a captação do herbicida pelos pneumócitos do tipo I e I(16); corticosteróides, como metilprednisolona, em altas doses, a fim de interferir no metabolismo lipídico para bloquear as fosfolipases da membrana celular, prevenindo, assim, a lipoperoxidação e reduzindo a reação inflamatória ${ }^{(55)}$.

O curcumin foi capaz de prolongar a sobrevivência de ratos intoxicados, protegendo os pulmões contra as injúrias que normalmente se estabelecem. Seu efeito provém da capacidade de prevenir o influxo de neutrófilos aos pulmões, estabilizar membranas celulares, diminuir oxidantes 
e aumentar antioxidantes celulares ${ }^{(73)}$. O 3-metil-1-fenil2-pirazolina-5-ona foi utilizado em ratos intoxicados com o herbicida e apresentou resultados favoráveis em termos de sobrevivência, se utilizado nas primeiras horas após a intoxicação. Sua ação antioxidante se deve à potente inibição que exerce sobre a atividade da lipoxigenase e sobre a peroxidação lipídica ${ }^{(60)}$.

Outras medidas gerais de suporte incluem a administração de fluidos e eletrólitos e o controle da dor. A suplementação de oxigênio deve ser evitada mesmo em casos de insuficiência respiratória, pois pode potencializar a injúria pulmonar provocada pelo estresse oxidativo(62).

\section{Conclusão}

A determinação dos níveis de paraquat, tanto séricos quanto urinários, é muito importante em casos de intoxi- cação e pode ser realizada através de técnicas analíticas diferentes, como cromatografia, eletroforese capilar e imunoensaios, mas na rotina clínica de urgências toxicológicas, o teste qualitativo com ditionito de sódio ainda é o mais utilizado. Os parâmetros bioquímicos também representam dados importantes na avaliação da extensão dos danos causados pelo herbicida, que provoca lesões graves em vários órgãos e pode levar à morte devido à falência respiratória.

Embora os primeiros casos de intoxicação fatal tenham sido relatados há mais de 40 anos e existam muitos artigos publicados a respeito, o mecanismo de toxicidade permanece não totalmente elucidado, e instituir novas e eficazes formas de tratamento para pacientes intoxicados ainda é um desafio. A eficácia das terapias mais recentemente desenvolvidas continua sob avaliação, sendo necessários mais estudos clinicotoxicológicos sobre o assunto.

\section{Referências}

I. ARYS, K. et al. Quantitative determination of paraquat in fatal intoxication by HPLC-DAD following chemical reduction with sodium borohydride. J Anal Toxicol, v. 24, n. 2, p. 116 2I, 2000

2. AUTOR, A. P. Reduction of paraquat toxicity by superoxide dismutase. Life Sci, v. 14, n. 7, p. 1309-19, 1974

3. BAJO BAJO, A. et al. Fatal paraquat poisoning. An Med Interna, v. I3, n. 2, p. 79-80, 1996

4. BATEMAN, D. N. Pharmacological treatments of paraquat poisoning. Hum Toxicol, v. 6, n. I, p. 57-62, 1987

5. BLOCK, E. R. Potentiation of acute paraquat toxicity by vitamin E deficiency. Lung, v. I56, n. 3, p. 195-203, 1979.

6. BOTTELA DE MAGLIA,J.:TARIN,J. E. B. Intoxicación por paraquat. Estudio de 29 casos y evaluación del tratamiento con la "pauta caribeña". Med Clin (Barc), v. I I 5, p. 530-3, 2000.

7. BOWLES, M. R. et al. Quantitation of paraquat in biological samples by radioimmunoassay using a monoclonal antibody. Fund Appl Toxicol, v. 19, n. 3, p. 375-9, 1992.

8. BROOKS, A. I. et al. Paraquat elicited neurobehavioral syndrome caused by dopaminergic neuron loss. Brain Res, v. 823, n I-2, p. I-10, 1999.

9. BRUNETTO, M. R. et al. Determination of paraquat in human blood plasma using reversed-phase ion-pair highperformance liquid chromatography with direct sample injection. Talanta, v. 59, p. 913-21, 2003.

10. BULLIVANT, C. M. Accidental poisoning by paraquat: report of two cases in man. BrMed J, v. 5498, p. 1272-3, 1966.

I I. BUS, J. S.;AUST, S. D.; GIBSON, J. E. Lipid peroxidation: a possible mechanism for paraquat toxicity. Res Commun Chem Pathol Pharmacol, v. II, n. I, p. 3I-8, 1975.
12. CAGNOLI, C. M. et al. Melatonin protects neurons from singlet oxygen-induced apoptosis. J Pineal Res, v. 18, n. 4, p. 222-6, 1995.

13. CALDAS, L. Q.A. Intoxicações exógenas agudas por carbamatos, organofosforados, compostos bipiridílicos e piretróides. Rio de Janeiro: Centro de Controle de Intoxicações de Niterói, 2000.

14. CHAN, B. S. H. et al. The renal excretory mechanisms and the role of organic cations in modulating the renal handling of paraquat. Pharmacol Therap, v. 79, n. 3, p. 193-203, 1998.

15. CHANDRASIRI, N.The first ever report of homicidal poisoning by intramuscular injection of Gramoxone (paraquat). Ceylon Med J, v. 44, n. I, p. 36-9, 1999.

16. CHEN, N.; BOWLES, M. R.; POND, S. M. Prevention of paraquat toxicity in suspensions of alveolar type II cells by paraquat-specific antibodies. Hum Exp Toxicol, v. I3, n. 8, p. 55।-7, 1994.

17. CORASANITI, M. T. et al. Distribution of paraquat into the brain after its systemic injection in rats. Funct Neurol, v. 7, n. I, p. 5I-6, 1992.

18. COXON, R. E.et al. Development of a simple, fluoroimmunoassay for paraquat. Clin Chim Acta, v. 175, n. 3, p. 297-305, 1988.

19. CROES, K.; MARTENS, F.; DESMET, K. Quantitation of paraquat in serum by HPLC.J Anal Toxicol, v. 17, n. 5, p. 310-2, 1993.

20. DENEKE, S. M. Thiol-based antioxidants. Curr Top Cell Regul, v. 36, p. I5I-80, 2000

2I. DRAFFAN, G. H. et al. Quantitative determination of the herbicide paraquat in human plasma by gas chromatographic and mass spectrometric methods. J Chromatogr, v. I39, n. 2, p. $311-20,1977$. 
22. ECOBICHON, D. J.Toxic effects of pesticides. In:AMDUR, M. O., DOULL, J., KLAASE, C. D. (ed). Casarett and Doull's Toxicology: the basic science of poisons. 4. ed. New York: Mc Graw Hill, 1991. Cap. 22, p. 763-810.

23. ERICKSON,T.et al. A case of paraquat poisoning and subsequent fatality presenting to an emergency department. J Emerg Med, v. I5, n. 5, p. 649-52, 1997.

24. FARRINGTON, J. A. et al. Bipyridylium quaternary salts and related compounds. V. Pulse radiolysis studies of the reaction of paraquat radical with oxygen. Implications for the mode of action of bipyridyl herbicides. Biochim Biophys Acta, v. 314 , n. 3, p. 372-8I, 1973.

25. FATORI, D.; HUNTER, W. M. Radioimmunoassay for serum paraquat. Clin Chim Acta, v. 100, n. 2, p. 81-90, 1980.

26. FERREIRA, H. S. Praguicidas no Brasil: impactos ambientais e possíveis conseqüências de sua interação com a desnutrição humana. Rev Bras Saúde Ocup, v. 80, p. 5I-60, 1993.

27. FORGET, G. Pesticides and the Third World. J Toxicol Environ Health, v. 32, n. I, p. II-31, I991.

28. FRITZ, K. L. et al. Acute intramuscular injection of oils or the oleic acid component protects mice against paraquat lethality. J Nutr, v. 124, n. 3, p. 425-9, 1994

29. FUKE, C. et al. Analysis of paraquat, diquat and two diquat metabolites in biological materials by high-performance liquid chromatography. Leg Med, v. 4, p. 156-63, 2002.

30. GARCIA, E. G. Segurança e saúde no trabalho rural com agrotóxicos: contribuição para uma abordagem mais abrangente. São Paulo, 1996. Dissertação (Mestrado) - Faculdade de Saúde Pública da Universidade de São Paulo.

31. GARNIER, R. et al. Paraquat poisoning by skin absorption: report of two cases. Vet Hum Toxicol, v. 36, n. 4, p. 31 3-5, 1994.

32. GIRI, S. N. et al. Effect of paraquat on plasma enzymes, insulin, glucose, and liver glycogen in the rat. Environ Res, v. 20, n. 2, p. 300-8, 1979.

33. HART, T. B.; NEVITT, A.; WHITEHEAD, A. A new statistical approach to the prognostic significance of plasma paraquat concentrations. Lancet, v. 24, p. 1222-3, 1984.

34. HOFFER, E. et al. $\mathrm{N}$-acetylcysteine increases the glutathione content and protects rat alveolar type II cells against paraquat-induced cytotoxicity. Toxicol Lett, v. 84, n. I, p. 7 12, 1996

35. HONG, S.Y. et al. Effect of vitamin C on plasma total antioxidant status in patients with paraquat intoxication. Toxicol Lett, $\mathrm{v}$ |26, p. 51-9, 2002.

36. HONORE, P. et al. Paraquat poisoning. "State of the art". Acto Clin Belg, v. 49, n. 5, p. 220-8, 1994

37. HOUZE, P.et al. Toxicokinetics of paraquat in humans. Hum Exp Toxicol, v. 9, n. I, p. 5-12, 1990.

38. HSU, H. H.; CHANG, C. T.; LIN, J. L. Intravenous paraquat poisoning-induced multiple organ failure and fatality: a report of two cases. J Toxicol Clin Toxicol, v. 4I, n. I, p. 87-90, 2003.

39. ITO, M. et al. Rapid analysis method for paraquat and diquat in the serum using ion-pair high-performance liquid chromatography. Biol Pharm Bull, v. 28, n. 4, p. 725-8, 2005.

40.KAWASE, S:;KANNO,S. Determination of the herbicides paraquat and diquat in blood and urine by gas chromatography. J Chromatogr A, v. 283, p. 231-40, 1984.
4I. KLEIN-SCHWARTZ, W.; SMITH, G. S. Agricultural and horticultural chemical poisonings: mortality and morbidity in the United States. Ann Emerg Med, v. 29, n. 2, p. 232-8, 1997.

42. LARINI, L. Herbicidas. In: LARINI, L. Toxicologia. 3. ed, São Paulo: Editora Manole LTDA, 1997. Cap.7, p. 199-203.

43. LHEUREUX, P. et al. Survival in a case of massive paraquat ingestion. Chest, v. 107, n. I, p. 285-9, 1995.

44. MELCHIORRI, D. et al. Paraquat toxicity and oxidative damage. Biochem Pharmacol, v. 5I, n. 8, p. 1095-9, 1996.

45. MØLCK, A. M.; FRIIS, C. The cytotoxic effect of paraquat to isolated renal proximal tubular segments from rabbits. Toxicology, v. I22, n. I-2, p. 123-32, 1997

46. MOLDEUS, P.; COTGREAVE, I. A.; BERGGREN, M. Lung protection by a thiol-containing antioxidant: $\mathrm{N}$-acetylcysteine. Respiration, v. 50, n. I, p. 31-42, 1986

47. NAITO, H.;YAMASHITA, M. Epidemiology of paraquat in Japan and a new safe formulation of paraquat. Hum Toxicol, v. 6 n. I, p. 87-8, 1987.

48. NIEWOLA, Z.; WALSH, S. T.; DAVIES, G. E. Enzymelinked immunosorbent assay (ELISA) for paraquat. Int $J$ Immunopharmacol, v. 5, n. 3, p. 21 I-8, 1983.

49. OGA, S. et al. Praguicidas. In: OGA, S. Fundamentos de toxicologia. 2. ed. São Paulo: Atheneu Editora, 2003. p. 437-58.

50. ONG, M. L.; GLEW, S. Paraquat poisoning: per vagina. Postgrad Med J, v. 65, p. 835-6, 1989.

5।. PAIXÃO, P. et al. Simple method for determination of paraquat in plasma and serum of human patients by highperformance liquid chromatography. I Chromatogr B, v. 775, p. 109-13, 2002

52. PATEL, M.; DAY, B. J. Metalloporphyrin class of therapeutic catalytic antioxidants. Trends Pharmacol Sci, v. 20, n. 9, p. 359-64, 1999.

53. PEDRAZZINI, G. B. et al. Fatal voluntary poisoning by parenteral paraquat. Schweiz Med Wochenschr, v. 121, n. 36, p. |293-7, 199|

54. PETER, B. et al. Role of lipid peroxidation and DNA damage in paraquat toxicity and the interaction of paraquat with ionizing radiation. Biochem Pharmacol, v. 43, n. 4, p. 705 15, 1992.

55. PONCE, P. et al. Tratamento da intoxicação por paraquat: plasmaférese vs. hemodiálise. Acta Med Port, v. 7, n. 5-6, p. 193-6, 1986

56. PROUDFOOT, A. T. et al. Paraquat poisoning: significance of plasma-paraquat concentrations. Lancet, v. 3|4, n. 8|38, p. 330-2, 1979

57. RIEGEL, W. Use of continuous renal replacement therapy for detoxification? Int J Artif Organs, v. 19, n. 2, p. III-2, 1996.

58. RIVERO GONZÁLES, A. et al. Intoxicación por paraquat: presentación de dos casos y revisión de la literatura. An Med Interna (Madrid), v. I8, n. 4, p. 208-10, 2001

59. RÜEG, E. F. Impacto dos agrotóxicos sobre o ambiente, a saúde e a sociedade. 2. ed. São Paulo: Ícone Editora, |991.

60. SAIBARA, T. et al. Protective effect of 3-methyl-I-phenyl-2pyrazolin-5-one, a free radical scavenger, on acute toxicity of paraquat in mice. Toxicol Lett, v. I43, p. 5 |-4, 2003. 
6I. SERRA, A.; DOMINGOS, F; MARTINS PRATA, M. Intoxicação por paraquat. Acta Med Port, v. 16, p. 25-32, 2003.

62. SITTIPUNT, C. Paraquat poisoning. Respir Care, v. 50, n. 3, p. 383-5, 2005

63. SMITH, P.; HEATH, D. Paraquat. CRC Crit Rev Toxicol, v. 4, n. 4, p. 4II-45, 1976.

64. SUGIHARA, N.; SUETSUGO,T.; FURUNO, K. High susceptibility to paraquat-driven lipid peroxidation of cultured hepatocytes loaded with linolenic acid. J Pharmacol Exp Ther, v. 274, n. I, p. 187-93, 1995.

65. SUNTRES, Z. E. Role of antioxidants in paraquat toxicity. Toxicology, v. I80, n. I, p. 65-77, 2002.

66. SUZUKI, K. et al. A new method for predicting the outcome and survival period in paraquat poisoning. Hum Exp Toxicol, v. 8, n. I, p. 33-8, 1989.

67. SUZUKI, K. et al. Effect of aggressive haemoperfusion on the clinical course patients with paraquat poisoning. Hum Exp Toxicol, v. 12, n. 4, p. 323-7, 1993.

68. TABAK, A.; TAITELMAN, U.; HOFFER, E. Percutaneous permeability to paraquat: in vitro experiments with human skin. J Toxicol Cut OcularToxicol, v. 9, p. 30 I- I I, 1990.
69. TABATA, N. et al. Paraquat myopathy: report on two suicide cases. Forensic Sci Int, v. 100, n. I-2, p. I 17-26, 1999.

70. TEARE, R. D. Poisoning by paraquat. Med Sci Law, v. I6, n. I, p. 9-12, 1976

7I.TOMITA, M.; OKUYAMA,T.; NIGO,Y. Simultaneous determination of paraquat and diquat in serum using capillary electrophoresis. Biomed Chromatogr, v. 6, n. 2, p. 91-4, 1992.

72.TSUNENARI, S.The determination of paraquat using thin-layer chromatography. Foren Sci, v. 5, n. I, p. 6I-7, 1975.

73. VENKATESAN, N. Pulmonary protective effects of curcumin against paraquat toxicity. Life Sci, v. 66, n. 2, p. 21-8, 2000.

74. VINNER, E. et al. Separation and quantification of paraquat and diquat in serum and urine by capillary electrophoresis. Biomed Chromatogr, v. I 5, n. 5, p. 342-7, 200 I.

75.WHO - World Health Organization. Paraquat and Diquat, IPCS. Environ Health Criteria, v. 39, p. 191, 1984.

76. WU, W. S.; TSAI, J. L. Simultaneous determination of paraquat and diquat in urine capillary electrophoresis. Kaohsiung J Med Sci, v. I4, n. 2, p. 76-80, 1998.

77. XARAU, S. N.; LAITA,A. D.; Intoxicación por paraquat: un puzzle al que le faltan piezas. Med Clin (Barc), v. I I 5, p. 546-8, 2000. 